\title{
Updating the recommendations of the Working Group for the Preservation of Fertility in Oncological and Hematological Patients and Other Patients Treating Gonadier Therapies "ONCOFERTILITY" (GROF) of the Polish Society of Oncological Gynecology regarding cryopreserves and autologous transplant
}

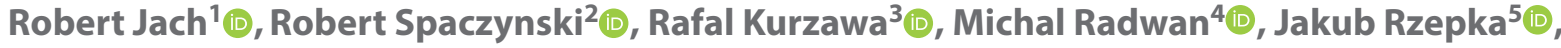 \\ Malgorzata Swornik ${ }^{6} \mathbb{C}$, Wojciech Pabian7 \\ ${ }^{1}$ Collegium Medicum, Jagiellonian University, Cracow, Poland \\ 2University of Medical Sciences, Department of Infertility and Reproductive Endocrinology, Poznan, Poland \\ ${ }^{3}$ Vitrolive, The Fertility Partnership, Szczecin, Poland \\ 4"Gameta" Infertility Treatment Clinic, Lodz, Poland \\ ${ }^{5}$ Maria Sklodowska-Curie National Research Institute of Oncology. Department of Gynecologic Oncology, Warsaw, Poland \\ ${ }^{6}$ Collegium Medicum, Jagiellonian University, Cracow, Poland \\ 7 University Hospital, Department of Gynecological Endocrinology and Gynecology, Cracow, Poland
}

Signatories: Prof. Theresa Woodruff- Oncofertility Consortium, Nortwestern University, Chicago III, USA

Patient Organization: Rak'n'Roll Foundation Win a Life! Warsaw, Poland

\begin{abstract}
Update of the recommendations of the Fertility Preservation Working Group in Oncological, Hematological and Other Patients Treated with Gonadotoxic Therapies "ONCOFERTILITY" (GROF) of the Polish Society of Oncological Gynecology regarding cryopreservation and autologous ovarian tissue transplantation.

The Fertility Preservation Working Group in Oncological, Hematological and Other Patients Treated with Gonadotoxic Therapies "ONCOFERTILITY" (GROF) of the Polish Society of Oncological Gynecology has developed current clinical guidelines and recommendations to improve the quality of healthcare provision in the area of reproductive health in patients undergoing therapy that may impair their reproductive potential.

The guidelines are based on current scientific evidence available at the time of writing this document. In the absence of scientific evidence on some aspects, a consensus was reached among GROF stakeholders.

The purpose of the guidelines is to assist healthcare professionals in making decisions in specific clinical situations regarding the selection of an appropriate and effective diagnostic and therapeutic process. The document provides practical guidelines for the management of cryopreservation and autologous ovarian tissue transplantation.
\end{abstract}

Ginekologia Polska 2021; 92, 9: 668-672

\section{INTRODUCTION}

In fewer and fewer countries, using ovarian tissue cryopreservation (OTC) as a method of preserving fertility in women who require chemotherapy is still considered an experimental treatment. In Poland, in accordance with the 2017 recommendations of the Polish Cancer Society's Working Group for the Preservation of Fertility in Cancer Patients (GROF), it was recommended that OTC be used only

\footnotetext{
Corresponding author:

Robert Jach

Collegium Medicum, Jagiellonian University, Cracow, Poland

e-mail: robert.jach@uj.edu.pl
}

This article is available in open access under Creative Common Attribution-Non-Commercial-No Derivatives 4.0 International (CC BY-NC-ND 4.0) license, allowing to download articles and share them with others as long as they credit the authors and the publisher, but without permission to change them in any way or use them commercially. 
in centers with appropriate experience [1], using protocols approved by the Bioethics Committee.

However, due to the increasing use of OTC as a method of securing fertility prior to systemic treatment around the world and increasing evidence of its effectiveness, this method is no longer considered a medical experiment. In the 2019 recommendations of the Executive Committee of the American Society for Reproductive Medicine (ASRM) [2], we read that OTC is no longer considered an experimental method and is the only option for prepubertal girls and those women who cannot be stimulated for an IVF procedure. The European Society of Human Reproduction and Embryology (ESHRE) has also changed its position on OTC and in the recommendations of 2020 [3] we read that ovarian tissue freezing may be proposed as an alternative treatment to preserve fertility in young patients who are at risk of developing premature ovarian insufficiency (POI).

\section{ADVANTAGES AND LIMITATIONS OF OTC (OVARIAN TISSUE CRYOPRESERVATION)}

OTC can be used in prepubertal girls, in women who do not have time or are not advised to stimulate ovulation prior to oncological intervention and in those who do not accept assisted reproductive techniques. In addition, it should be noted that the collection and retransplantation of ovarian tissue (OTT) is the only method of securing fertility that allows conception without further medical interventions. It is also a method of restoring the hormonal function of the ovary and, consequently, a cardioprotective effect, reducing the risk of osteoporosis and senile dementia, which with such a high percentage of autograft acceptance (95\%) seems no less important than procreation itself [4]. The disadvantage of this method is the necessity to perform laparoscopy at least twice and the lack of reimbursement of costs of freezing ovarian tissue from public funds in Poland. In the case of hematological neoplasms, there is a theoretical risk related to the possibility of re-implantation of neoplastic cells in a frozen fragment of the ovary (depending on the type and stage of the neoplasm), but so far, no such case has been reported. [5]. Due to the risk of retransplantation of neoplastic cells in patients with haematological neoplasms, the collection of ovarian tissue in this group should be performed only after induction chemotherapy and complete remission of the tumor in the blood.

\section{EFFECTIVENESS}

OTC indications and exclusion criteria differ depending on the centers that carry them out. The age of the enrolled patients seems to be crucial. In various recommendations, we find the upper age limit from 35 years [6] to even 49 years [7-9]. However, pregnancy was rarely achieved in women over 35 years of age, and none over 38 years of age was found [10]. The effectiveness of this method for women younger than 36 years is confirmed by the study, which compared the effectiveness of OTC in comparison with oocyte cryopreservation (OC). It showed the superiority of OC for women over 36 years of age, in whom $30 \%$ of pregnancies obtained with this method were found, while no pregnancies were achieved with the OTC method. In the group of younger patients, the effectiveness of both methods was comparable [11]. By 2019, autologous ovarian tissue transplantation was performed in over 300 patients, over 140 pregnancies obtained by this method were reported, of which over 100 children were born. In $85 \%$ of cases, ovarian tissue cryotransplant function was restored within four months. The effectiveness of the method was assessed at $40 \%$, counting at least one child per patient treated with this method [10, 12]. More recent data estimate the efficacy of ovarian tissue autograft measured as restoration of menstrual function and a reduction in $\mathrm{FSH}<20 \mathrm{IU} / \mathrm{mL}$ as $94 \%$, while the return of procreative function, measured as at least one pregnancy, was estimated at $50 \%$, and delivery to nearly $42 \%$ [4]. Unfortunately, there is no data on the number of babies born for all women who started treatment with this method, and a relatively low number of procedures performed. The largest percentage of patients undergoing the OCT procedure are patients with breast cancer. In this group of women, the damage to the ovarian tissue structure as a result of chemotherapy occurs not only by damaging the DNA structure in egg cells and granular cells, but also by accelerating the recruitment of primordial follicles [13]. Recently, the loss of the ovarian reserve through oocyte apoptosis has also been postulated [14]. Therefore, it seems that special emphasis should be placed on the collection of ovarian tissue before the implementation of systemic therapy in neoplasms other than hematological.

\section{OVARIAN FRAGMENT CRYOPRESERVATION PROCEDURE - OTC}

There are two methods of collecting ovarian tissue:

1. Ovarian cortex biopsy $1 / 3-2 / 3$ ovarian surface (OCB), used for large ovaries or high ovarian reserve $(\mathrm{AMH}>2)$.

2. Unilateral removal of the ovary in the case of low ovarian reserve, small ovaries.

The treatment can be performed on any day of the cycle. The collected tissue must be transported to the reference embryology laboratory under strict conditions within 1-20 hours [5].

There are no studies comparing the effectiveness of both methods of obtaining ovarian tissue. The advantage of OCB is that it leaves both ovaries as a potential site for ovarian tissue transplantation and reduces the invasiveness of the procedure. A potential disadvantage of removing 
one ovary is the acceleration of menopause after chemotherapy/radiotherapy, although no comparative studies have been performed in these groups of patients [10].

Preparation for cryopreservation consists of dividing the ovarian cortex in sterile conditions into fragments of approximately $1 \mathrm{~mm}$. This is because effective freezing requires tissue thickness up to $2 \mathrm{~mm}$, and that the vast majority of primordial follicles are located less than $1 \mathrm{~mm}$ from the ovary surface. The fragments prepared in this way are individually frozen by slow freezing or vitrification. The 2018 study describes the recovery of pregnancy from ovarian tissue retransplantation, frozen using the slow-freezing method and stored for over 14 years. Since the procedure of ovarian tissue collection cannot be repeated, the preparation and freezing of the tissue should be performed by trained embryologists and in appropriately adapted laboratories.

\section{OVARIAN TISSUE TRANSPLANTATION (OTT)}

Autotransplantation of ovarian fragments can be done either orthotropically or heterotropically. The orthotropic sites are the remaining ovaries, the broad ligament, and the peritoneal pocket at the ovary. There were no significant differences between these sites [10].

Heterotropic sites for autotransplantation of ovarian fragments have been described, such as the subcutaneous tissue of the forearm and abdominal integuments, or only one birth from heterotropic transplantation [15], while the rest from orthotropic location, with as many as $60 \%$ of these pregnancies conceived naturally.

Patients who became pregnant after OTT were on average younger than those who failed ( $26.4 \pm 6.3$ vs $29.6 \pm 5.4$ years) [10]. One group describes the inclusion criteria for OCT based on the age of patients under 35 years of age and the measurement of ovarian reserve (AMH above $0.4 \mathrm{ng} / \mathrm{mL}$ and AFC $>5$ antral follicles) [16]. The average ovarian transplant lifetime is 24.9 month (4-144 months), three live births over seven years after OTT were described in one patient [10].

There is no consensus on the amount/volume of ovarian tissue transplanted. In a meta-analysis of 309 OTT, 255 women had 1/3 ovaries transplanted, and 45 patients who required two transplants to become pregnant were also reported. Three such procedures were described in only one percent of cases. There is also no universally accepted upper age limit for women undergoing OTT. The oldest reported patients were 47 years old and in these cases, attention is drawn to the maternal risk associated with pregnancy $[10,17]$.

\section{OTHER METHODS COMBINED WITH OTC}

In order to increase the chances of getting pregnant, the ESHRE recommendations allow the combination of OTC with other fertility preservation techniques, such as OC (oocyte cryopreservation) and the movement of the ovaries beyond the small pelvis when irradiation in this area is necessary. In the case of oocyte cryopreservation, it is recommended to stimulate ovulation immediately after the OTC procedure or immediately before [3].

\section{SAFETY OF THE METHOD Surgical complications}

Both the collection of ovarian tissue and its retransplantation are associated with a low risk of surgical complications, estimated at about one percent $[18,19]$. Retransplantation surgery may be combined with other procedures, such as hysteroscopy, tubal patency assessment, and other procedures depending on the clinical context. It is recommended that the OTT procedure and ovarian thawing take place in the same facility. Although there are no reports of infectious complications, it is recommended to consider prophylactic perioperative antibiotic therapy.

\section{Risk of reintroducing cancer cells}

Ovarian metastases are found in slightly more than $20 \%$ of autopsies in women who died due to non-gynecological neoplastic diseases. For this reason, the decision about OTT should be made with utmost caution in patients suffering from leukemia and CSN neoplasms, such as medulloblastoma or neuroblastoma. In other neoplasms, OTT seems safe if the invasion of small pelvis is excluded. For this reason, it seems unlikely that the risk of reintroduction of cancer cells in ovarian and adnexal cancers (even in the case of graft removal after pregnancy) could be so limited that OTT could be recommended as safe in these cancers. Before OTT, the patient should be in good condition and cured oncologically in accordance with the accepted treatment criteria. After retransplantation, she should be subject to at least two years of oncological follow-up [5]. It seems reasonable to perform a histopathological examination of an ovarian section taken during the OTC procedure, as well as another histopathological inspection before cryopreservation of the tissue.

\section{Perinatal complications}

Recent meta-analyzes in patients after cancer treatment indicate an increased risk of prematurity (RR 1.56; $95 \% \mathrm{Cl}$ 1.37-1.77 - mainly due to oncological indications for early termination of pregnancy), low birth weight (RR $1.47 ; 95 \% \mathrm{Cl}$ 1.24-1.73), urgent Caesarean sections (1.22; 95\% Cl 1.15-1.30), elective cesarean sections (RR 1.38; 95\% Cl 1.13-1.70), and postpartum haemorrhages (RR 1.18; 95\% Cl 1.02-1.36) [20].

\section{Risk to the fetus}

There is no evidence of an additional risk of fetal malformations after OTT $[10,21]$. The risk is about $1.2 \%$, which is comparable with the occurrence of major fetal malforma- 
tions in the general population [17]. The latest data on the occurrence of fetal malformations in 22 patients who underwent the first course of chemotherapy before OTC indicate the birth of eight healthy children from 13 pregnancies [22].

\section{Long-term risk}

As the first cryotransplantation took place almost 20 years ago and there are no reports of negative breasts related to this method, the long-term risk should be assumed to be low. A separate problem is patients treated for breast cancer with mutations in the BRCA1 or BRCA2 genes. In these patients, a site of transplantation (heterotropic transplantation) may be considered, where the observation of the graft will be easier, or orthotropic transplantation, followed by removal of the appendages, as soon as possible after birth, to the number of children that the patient established, but not later than the age of $40[23,24]$.

\section{RECOMMENDATIONS OF THE WORKING GROUP}

1. The Working Group recommends the recognition of the OTC/OTT procedure as a therapeutic method.

2. It is recommended to consider OTC/OTT in patients with low ovarian reserve $(\mathrm{AMH}<0.4 \mathrm{ng} / \mathrm{mL}, \mathrm{AFC}<5$ follicles in both ovaries)

3. In the case of blood cancers and CSN, individual consideration of the case regarding the risk of tumor reimplantation seems justified.

4. It is recommended to use OTC after the initiation of chemotherapy only for hematological malignancies

\section{FINAL REMARKS}

The guidelines do not replace and do not override the individual responsibility of healthcare professionals to make the right decisions about the diagnosis and treatment of individual patients. Ultimately, it is healthcare professionals who make clinical decisions on a case-by-case basis, using their clinical judgment, knowledge and experience, and considering the condition, circumstances and wishes of the patient, in consultation with the patient and/or their caregiver and taking into account current guidelines issued by relevant public health organizations.

The team of experts reserves the right to update this statement in the event of new significant scientific reports.

These GROF guidelines are published for educational use only. Commercial use is not permitted. No part of the guidelines may be translated or copied in any form without the prior written consent of GROF.

\section{Conflict of interest}

None.

\section{REFERENCES}

1. Jach R, Pabian W, Spaczyński R, et al. Recommendations of the Fertility Preservation Working Group in Oncological, Hematological and Other Patients Treated With Gonadotoxic Therapies „ONCOFERTILITY” (GROF) of the Polish Society of Oncological Gynecology. J Adolesc Young Adult Oncol. 2017; 6(3): 388-395, doi: 10.1089/jayao.2017.0039, indexed in Pubmed: 28657411.

2. Practice Committee of the American Society for Reproductive Medicine. Electronic address: asrm@asrm.org. Fertility preservation in patients undergoing gonadotoxic therapy or gonadectomy: a committee opinion. Fertil Steril. 2019; 112(6): 1022-1033, doi: 10.1016/j.fertnstert.2019.09.013, indexed in Pubmed: 31843073.

3. Anderson RA, Amant F, Braat D, et al. ESHRE Guideline Group on Female Fertility Preservation. ESHRE guideline: female fertility preservation. Hum Reprod Open. 2020; 2020(4): hoaa052, doi: 10.1093/hropen/hoaa052, indexed in Pubmed: 33225079.

4. Shapira M, Dolmans MM, Silber S, et al. Evaluation of ovarian tissue transplantation: results from three clinical centers. Fertil Steril. 2020; 114(2): 388-397, doi: 10.1016/j.fertnstert.2020.03.037, indexed in Pubmed: 32605799

5. Andersen $C Y$, Bollerup $A C$, Kristensen SG. Defining quality assurance and quality control measures in connection with ovarian tissue cryopreservation and transplantation: a call to action. Hum Reprod. 2018; 33(7): 1201-1204, doi: 10.1093/humrep/dey105, indexed in Pubmed: 29718400.

6. Anderson RA, Wallace WH. Fertility preservation in girls and young women. Clin Endocrinol (Oxf). 2011; 75(4): 409-419, doi: 10.1111/j.136 5-2265.2011.04100.x, indexed in Pubmed: 21575025.

7. Jadoul P, Guilmain A, Squifflet J, et al. Efficacy of ovarian tissue cryopreservation for fertility preservation: lessons learned from 545 cases. Hum Reprod. 2017; 32(5): 1046-1054, doi: 10.1093/humrep/dex040, indexed in Pubmed: 28333228.

8. Karavani G, Schachter-Safrai N, Chill HH, et al. Single-Incision Laparoscopic Surgery for Ovarian Tissue Cryopreservation. J Minim Invasive Gynecol. 2018;25(3): 474-479, doi: 10.1016/j.jmig.2017.10.007, indexed in Pubmed: 29032255.

9. Lotz L, Maktabi A, Hoffmann I, et al. Ovarian tissue cryopreservation and retransplantation--what do patients think about it? Reprod Biomed Online. 2016; 32(4): 394-400, doi: 10.1016/j.rbmo.2015.12.012, indexed in Pubmed: 26825247.

10. Gellert SE, Pors SE, Kristensen SG, et al. Transplantation of frozen-thawed ovarian tissue: an update on worldwide activity published in peer-reviewed papers and on the Danish cohort. J Assist Reprod Genet. 2018; 35(4): 561-570, doi: 10.1007/s10815-018-1144-2, indexed in Pubmed: 29497953.

11. Diaz-Garcia C, Domingo J, Garcia-Velasco JA, et al. Oocyte vitrification versus ovarian cortex transplantation in fertility preservation for adult women undergoing gonadotoxic treatments: a prospective cohort study. Fertil Steril. 2018; 109(3): 478-485.e2, doi: 10.1016/j.fertnstert.2017.11.018, indexed in Pubmed: 29428307.

12. Pretalli JB, Frontczak Franck S, Pazart L, et al. DATOR Group. Development of Ovarian Tissue Autograft to Restore Ovarian Function: Protocol for a French Multicenter Cohort Study. JMIR Res Protoc. 2019; 8(9): e12944, doi: 10.2196/12944, indexed in Pubmed: 31573931

13. Dolmans MM, Taylor HS, Rodriguez-Wallberg KA, et al. Utility of gonadotropin-releasing hormone agonists for fertility preservation in women receiving chemotherapy: pros and cons. Fertil Steril. 2020; 114(4): 725-738, doi: 10.1016/j.fertnstert.2020.08.011, indexed in Pubmed: 33040981

14. Luan Yi, Edmonds ME, WoodruffTK, et al. Inhibitors of apoptosis protect the ovarian reserve from cyclophosphamide. J Endocrinol. 2019; 240(2): 243-256, doi: 10.1530/JOE-18-0370, indexed in Pubmed: 30530902.

15. Stern CJ, Gook D, Hale LG, et al. Delivery of twins following heterotopic grafting of frozen-thawed ovarian tissue. Hum Reprod. 2014; 29(8): 1828, doi: 10.1093/humrep/deu119, indexed in Pubmed: 24871346.

16. Paradisi $R$, Macciocca $M$, Vicenti $R$, et al. New insights in the selection and management of cancer patients applicants for ovarian tissue cryopreservation. Gynecol Endocrinol. 2016; 32(11): 881-885, doi: 10.1080/09513590.2016.1188373, indexed in Pubmed: 27227875.

17. Pacheco F, Oktay K. Current Success and Efficiency of Autologous Ovarian Transplantation: A Meta-Analysis. Reprod Sci. 2017; 24(8): 1111-1120, doi: 10.1177/1933719117702251, indexed in Pubmed: 28701069.

18. Beckmann MW, Dittrich R, Lotz $L$, et al. Operative techniques and complications of extraction and transplantation of ovarian tissue: the 
Erlangen experience. Arch Gynecol Obstet. 2017; 295(4): 1033-1039, doi: 10.1007/s00404-017-4311-2, indexed in Pubmed: 28197717.

19. Beckmann MW, Dittrich $\mathrm{R}$, Lotz $\mathrm{L}$, et al. Fertility protection: complications of surgery and results of removal and transplantation of ovarian tissue. Reprod Biomed Online. 2018; 36(2): 188-196, doi: 10.1016/j. rbmo.2017.10.109, indexed in Pubmed: 29198423.

20. van der Kooi ALLF, Kelsey TW, van den Heuvel-Eibrink MM, et al. Perinatal complications in female survivors of cancer: a systematic review and meta-analysis. Eur J Cancer. 2019; 111: 126-137, doi: 10.1016/j. ejca.2019.01.104, indexed in Pubmed: 30849686.

21. Imbert R, Moffa F, Tsepelidis S, et al. Safety and usefulness of cryopreservation of ovarian tissue to preserve fertility: a 12-year retrospective analysis. Hum Reprod. 2014; 29(9): 1931-1940, doi: 10.1093/humrep/deu158, indexed in Pubmed: 24958067.
22. Poirot C, Fortin A, Lacorte JM, et al. CAROLéLISA Cooperative Group Impact of cancer chemotherapy before ovarian cortex cryopreservation on ovarian tissue transplantation. Hum Reprod. 2019; 34(6): 1083-1094, doi: 10.1093/humrep/dez047, indexed in Pubmed: 31116405.

23. Lambertini M, Goldrat O, Ferreira AR, et al. Reproductive potential and performance of fertility preservation strategies in BRCA-mutated breast cancer patients. Ann Oncol. 2018; 29(1): 237-243, doi: 10.1093/annonc/mdx639, indexed in Pubmed: 29045555.

24. Lambertini M, Di Maio M, Poggio F, et al. Knowledge, attitudes and practice of physicians towards fertility and pregnancy-related issues in youngBRCA-mutated breast cancer patients. Reprod Biomed Online. 2019; 38(5): 835-844, doi: 10.1016/j.rbmo.2018.11.031, indexed in Pubmed: 30914152 